\title{
ANALISIS RISIKO KESELAMATAN DAN KESEHATAN KERJA PADA PROSES PRODUKSI STEEL BILLET DI PT X STEEL INDONESIA TAHUN 2019
}

\section{ANALYSIS RISK OF OCCUPATIONAL SAFETY AND HELATH IN THE STEEL BILLET PRODUCTION PROCESS AT PT X STEEL INDONESIA IN 2019}

\author{
Bella Nitia Pelga ${ }^{1}$, Dhini Easter Yanti ${ }^{1}$, Nova Muhani ${ }^{*}$ \\ ${ }^{1}$ Fakultas Kesehatan Masyarakat Universitas Malahayati, jl Pramuka No 27 \\ Kemiling Bandar Lampung Indonesia \\ Korespondensi Penulis : muhaninova@gmail.com
}

Penyerahan : 04-08-2020, Perbaikan : 13-12-2020, Diterima : 01-02-2020

\begin{abstract}
International labor organization (ILO) recorded that every 15 seconds one worker and 160 workers suffer occupational illness worldwide. In indonesia, there were 123,000 occupational accident cases in 2017. PT X Steel Indonesia is a company that manufactures steel. PT $X$ Steel Indonesia employees is a reason for researchers to choose PT $X$ Steel Indonesia. The objective of this study was to identify the risk level of occupational health and safety during production process of steel billet at PT X Steel Indonesia. The research is a descriptive observational to identify potential hazards and to analyze occupational accident risk. The subjects of this research consisted of 11 informants. The hazard analysis technique was job hazard analysis (jha) and the risk analysis was through semi-quantitative technique which refers to as/nzs 4360: 2004 thatmultiply consequence, exposure and likelihood to determine risk level. The result of this research showed that the risk level varied from acceptable for ten risks (28\%), priority 3 for eleven risks (30\%) and substantial for 15 risks (42\%). It is recommended that the company do noise exposure measurement, organize ergonomic training, add self- protection equipment, and add safety sign in the manufacture area.
\end{abstract}

Keywords : as/nzs 4630:2004, consequence, exposure, likelihood, level of risk

\begin{abstract}
Abstrak
International labour organization (ILO) mencatat 1 pekerja di dunia meninggalsetiap 15 detik karena kecelakaan kerja. Angka kecelakaan kerja di Indonesia pada tahun 2017 sebesar 123.000 kasus kecelakaan kerja di PT X Steel Indonesia bergerak di sektor besi baja. Bahan baku pembuatan besi baja yang digunakan adalah scrap yang di proses melalui proses pemilahan scrap, cooking scrap, analisis laboraturium dan pencetakan. Adanya pemberitaan tentang kecelakaan kerja yang dialami karyawan PT X Steel Indonesia menjadi alasan bagi peniliti untukmemilih PT $X$ Steel Indonesia. Tujuan penelitian ini mengetahui tingkat risiko keselamatan dan kesehatan kerja pada proses produksi steel billet di PT $\mathbf{x}$ Steel Indonesia. Jenis penelitian deskriftif observasional untuk mengidentifikasi bahaya dan menganalisis risiko kecelakaan kerja. Subyek penelitian sebanyak 11 informan. Identifikasi bahaya menggunakan teknik job hazard analysis (jha) dan analisa risiko menggunakan teknik semi kuantitatif yang mengacu pada standar as/nzs 4360:2004 yang mengalikan nilai consequence, exposure, likelihood untuk menentukan tingkat risiko. Hasil penelitian yang didapatkan dengan tingkat risiko acceptable sebanyak 10 risiko (28\%), priority 3 sebanyak 11 risiko (30\%) dan 15 risiko (42\%) pada tingkat substantial. Melakukan pengukuran pajanan bising, pelatihan ergonomi, menambah alat pelindung diri (apd) sesuai dengan jumlah pekerja dan menambah safety sign.
\end{abstract}

Kata kunci : as/nzs 4360:2004, konsekuensi, pajanan, kemungkinan, level risiko. 


\section{PENDAHULUAN}

Keselamatan dan kesehatan kerja adalah segala kegiatan untuk menjamin dan melindungi keselamatan dan kesehatan tenaga kerja melalui upaya pencegahan kecelakaan kerja dan penyakit akibat kerja. (Peraturan Menteri Ketenagakerjaan RI, 2018).

International Labor Organization (ILO), mencatat 2,78 juta pekerja meninggal setiap tahun karena kecelakaan kerja dan penyakit akibat kerja. (Internasional Labour Organization, 2018).

Angka kecelakaan kerja di Indonesia pada tahun 2014 terdapat 105.385 kasus kecelakaan kerja. Tahun 2015 menjadi 110,285. Tahun 2016 sebanyak 105.182. Tahun 2017 sebesar 123.000 kasus kecelakaan kerja. (BPJS Ketenagakerjaan, 2016).

Angka kecelakaan kerja provinsi Lampung tahun 2014 sebanyak 90 kasus yang menempati posisi tiga terendah dari seluruh Provinsi di Indonesia. (Kementerian Kesehatan RI, 2015).

PT $X$ Steel Indonesia merupakan industri yang bergerak di sektor besi baja. Produk yang dihasilkan adalah steel billet dan besi beton. Steel billet terbuat dari bahan baku besi tua atau besi bekas. Proses kerja produksi steel billet yang dilakukan di PT X Steel Indonesia adalah proses scrap, proses cooking scrap, analisis laboraturium dan proses pencetakan. Angka kecelakaan kerja di PT $X$ Steel Indonesia terjadi setiap tahunnya tahun 2015 terdapat 21 kasuskecelakaan kerja. Tahun 2016 menurun menjadi 13 kasus kecelakaan kerja. Tahun 2017 terdapat 13 kasus kecelakaan kerja. Pada tahun 2018 terhitung Januari-April terdapat 8 kasus kecelakaan kerja.

PT $X$ Steel Indonesia belum ada kegiatan analisis risiko, adanya kecelakaan kerja disetiap tahun yang dialami karyawan PT $X$ Steel Indonesia menjadi alasan bagi peniliti untuk memilih PT $X$ Steel Indonesia menjadi lokasi penelitian, dimana penggunaan berbagai mesin dalam proses produksi steel billet dapat menyebabkan banyak risiko keselamatandan kesehatan kerja di perusahaan tersebut. Oleh karena itu, peneliti ingin melakukan analisis risiko pada proses produksi steel billet di PT
San Xiong Steel Indonesia untuk mengetahui tingkat risiko. baik (AS/NZS 4360:1999, 1999).

\section{METODE PENELITIAN}

Desain dalam penelitian ini
menggunakan desain deskriftif observasional. Metode yang digunakan untuk penilaian risiko adalah metode analisis risiko semi kuantitatif yang mengacu pada standar AS/NZS 4360:2004. Penelitian ini dilakukan di PT $X$ Steel Indonesia pada bulanJanuariFebruari 2019, dengan jumlah informan sebanyak 11 informan.

Data yang digunakan dalam penelitian ini adalah pertanyaan dengan menggunakan wawancara semi terstruktur, sedangkan Lembar observasi menggunakan job hazard analysis form. Pengolahan data dilakukan dengan menggunakan tabel JHA, sedangkan data dianalisis dengan menggunakan metode analisis risiko semi kuantitatif, yakni dengan metode W.T. Fine untuk melihat seberapa besar tingkat risiko yaitu dengan mengalikan consequence exposure dan likelihood.

Analisis risiko keselamatan dan kesehatan kerja yang terintegrasi kedalam manajemen risiko dimulai dengan tahap pertama yaitu identifikasi risiko menggunakan metode job hazard analysis (JHA) dengan tujuan mendapatkan risk event. Menurut OSHA 3071, JHA merupakan teknik yang berfokus pada tahapan pekerjaan sebagai cara untuk mengidentifikasi bahaya sebelum kejadian yang tidak diinginkan terjadi. JHA fokus pada interaksi antara pekerja, pekerjaan, peralatan, dan lingkungan kerja (U.S. Departmen Of Labor, 2018). Tahap kedua melakukan analisis risiko untuk menentukan besarnya suatu risiko menggunakan analisis semi kuantitatif dengan metode W.T. Fine. Tahap ketiga, evaluasi risiko dengan membandingkan tingkat risiko yang ditemukan selama proses analisis risiko dengan kriteria yang sudah ditetapkan sebelumnya (AS/NZS 4360:2004, 2006). Tahap terahir adalah pengendalian risiko untuk menghilangkan atau mengurangi risikoyang kurang. 
HASIL

Tabel 1

Penilaian bahaya dan risiko proses scrap

\begin{tabular}{|c|c|c|c|c|c|c|c|c|c|c|c|c|}
\hline \multirow[t]{2}{*}{ No. } & \multirow[t]{2}{*}{ Proses } & \multirow[t]{2}{*}{ Risiko } & \multirow[t]{2}{*}{ Dampak } & \multicolumn{3}{|c|}{$\begin{array}{c}\text { Analisis Basic } \\
\text { Risik }\end{array}$} & \multirow[t]{2}{*}{$\begin{array}{c}\text { Nilai } \\
\text { Risiko }\end{array}$} & \multirow[t]{2}{*}{ Pengendalian Yang Ada } & \multicolumn{3}{|c|}{$\begin{array}{c}\text { Analisis } \\
\text { Existing Risk }\end{array}$} & \multirow[t]{2}{*}{$\begin{array}{l}\text { Nilai } \\
\text { Risiko }\end{array}$} \\
\hline & & & & $\mathrm{C}$ & $E$ & $\mathrm{~L}$ & & & C & $\mathrm{E}$ & $\mathrm{L}$ & \\
\hline \multirow[t]{2}{*}{1 , } & \multirow[t]{2}{*}{$\begin{array}{l}\text { Pemilahan } \\
\text { raw } \\
\text { material }\end{array}$} & $\begin{array}{l}\text { Tertimpa material } \\
\text { atau hoist crane }\end{array}$ & $\begin{array}{l}\text { - Memar } \\
\text { - Cidera } \\
\text { - Tulang patah }\end{array}$ & 25 & 10 & 0,5 & 125 & $\begin{array}{l}\text { - Safety helmet } \\
\text { - Safety shoes } \\
\text { - Safety sign } \\
\text { - Baju safety } \\
\text { - Briefing } \\
\text { - SOP }\end{array}$ & 15 & 10 & 0,1 & 15 \\
\hline & & Terpapar kebisingan & $\begin{array}{l}\text { - Ketidaknyamanan } \\
\text { - Gangguan } \\
\text { pendengaran }\end{array}$ & 5 & 10 & 3 & 150 & Tidak ada & 5 & 10 & 3 & 150 \\
\hline \multirow[t]{5}{*}{2.} & \multirow{3}{*}{$\begin{array}{l}\text { Pemotonga } \\
\mathrm{n} \text { besi } \\
\text { menggunak } \\
\text { an mesin } \\
\text { cutting }\end{array}$} & Tangan terjepit & $\begin{array}{l}\text { - Memar } \\
\text { - Terpotong } \\
\text { - Kecacatan }\end{array}$ & 25 & 10 & 0,5 & 125 & $\begin{array}{l}\text { - Sarung tangan } \\
\text { - Briefing } \\
\text { - Safety sign } \\
\text { - SOP }\end{array}$ & 15 & 10 & 0,1 & 15 \\
\hline & & Terpapar kebisingan & $\begin{array}{l}\text { - Ketidaknyamanan } \\
\text { - Gangguaan } \\
\text { pendengaran } \\
\end{array}$ & 5 & 10 & 3 & 150 & Tidak Ada & 5 & 10 & 3 & 150 \\
\hline & & Posisi janggal & $\begin{array}{l}\text { - Kaku otot } \\
\text { - Kelelahan }\end{array}$ & 5 & 10 & 3 & 150 & $\begin{array}{l}\text { - Training } \\
\text { - Pergantian kerja }\end{array}$ & 1 & 10 & 3 & 30 \\
\hline & \multirow{2}{*}{$\begin{array}{l}\text { Pemotonga } \\
\mathrm{n} \text { besi } \\
\text { menggunak } \\
\text { an gas }\end{array}$} & $\begin{array}{l}\text { Mata terkena } \\
\text { cahaya }\end{array}$ & Sakit mata & 5 & 10 & 3 & 150 & Face shield & 5 & 10 & 3 & 150 \\
\hline & & $\begin{array}{l}\text { Mata terkena } \\
\text { percikan }\end{array}$ & $\begin{array}{l}\text { - Iritasi mata } \\
\text { - Kerusakan mata }\end{array}$ & 5 & 10 & 3 & 150 & Fae shield & 1 & 10 & 1 & 10 \\
\hline
\end{tabular}




\begin{tabular}{|l|l|l|c|c|c|c|c|c|c|c|}
\hline \multirow{2}{*}{ cutting } & $\begin{array}{l}\text { Kulit terkena } \\
\text { percikan }\end{array}$ & Luka bakar & 5 & 10 & 3 & 150 & $\begin{array}{l}\text { - Baju safety } \\
- \text { Safety shoes } \\
- \text { Sarung tangan } \\
\text { - Face shield }\end{array}$ \\
\cline { 2 - 8 } & Menghirup asap & $\begin{array}{l}\text { - Sesak nafas } \\
\text { - Gangguan }\end{array}$ & 5 & 10 & 3 & 150 & $\begin{array}{l}\text { Membelakangi arah } \\
\text { angin }\end{array}$ & 10 & 10 \\
\hline
\end{tabular}




\begin{tabular}{|c|c|c|c|c|c|c|c|c|c|c|c|c|}
\hline & & & pernafasan & & & & & & & & & \\
\hline & & Terpapar kebisingan & $\begin{array}{l}\text { - Ketidaknyamanan } \\
\text { - Gangguam } \\
\text { pendengaran }\end{array}$ & 5 & 10 & 3 & 150 & Tidak ada & 5 & 10 & 3 & 150 \\
\hline & & Posisi janggal & $\begin{array}{l}\text { - Kram kaki } \\
\text { - Nyeri punggung }\end{array}$ & 5 & 10 & 3 & 150 & $\begin{array}{l}\text { - Training } \\
\text { Pergantian kerja }\end{array}$ & 1 & 10 & 3 & 30 \\
\hline \multirow[t]{2}{*}{3.} & \multirow[t]{2}{*}{$\begin{array}{l}\text { Meletakkan } \\
\text { besi ke dalam } \\
\text { bak besi }\end{array}$} & $\begin{array}{l}\text { Tertimpa material } \\
\text { atau hoist crane }\end{array}$ & $\begin{array}{l}\text { - Tulang patah } \\
\text { - Kerusakan } \\
\text { properti }\end{array}$ & 25 & 10 & 0,5 & 125 & $\begin{array}{l}\text { - Safety helmet } \\
\text { - Safety shoes } \\
\text { - Safety sign } \\
\text { - Baju safety } \\
\text { Briefing }\end{array}$ & 15 & 10 & 0,1 & 15 \\
\hline & & Terpapar kebisingan & $\begin{array}{l}\text { - Ketidaknyamanan } \\
\text { - Gangguan } \\
\text { pendengaran }\end{array}$ & 5 & 10 & 3 & 150 & Tidak ada & 5 & 10 & 3 & 150 \\
\hline \multirow[t]{3}{*}{4.} & \multirow[t]{3}{*}{ Press besi } & Tergores material & $\begin{array}{l}\text { - Terluka } \\
\text { - Cidera ringan }\end{array}$ & 1 & 10 & 3 & 30 & $\begin{array}{l}\text { - Baju safety } \\
\text { - Safety helmet } \\
\text { Sarung tangan }\end{array}$ & 1 & 10 & 1 & 10 \\
\hline & & Tertusuk material & $\begin{array}{l}\text { - Terluka } \\
\text { - Cidera ringan }\end{array}$ & 1 & 10 & 6 & 60 & $\begin{array}{l}\text { - Safety shoes } \\
\text { - Briefing } \\
\text { Sarung tangan }\end{array}$ & 1 & 10 & 3 & 30 \\
\hline & & Terpapar kebisingan & $\begin{array}{l}\text { - Ketidaknyamanan } \\
\text { - Ketulian gangguan } \\
\text { pendengaran }\end{array}$ & 5 & 10 & 3 & 150 & Tidak ada & 5 & 10 & 3 & 150 \\
\hline \multirow[t]{2}{*}{5.} & \multirow[t]{2}{*}{$\begin{array}{l}\text { Pemindahan } \\
\text { besi } \\
\text { kepanggung } \\
\text { tungku }\end{array}$} & $\begin{array}{l}\text { Tertimpa material } \\
\text { atau hoist crane }\end{array}$ & $\begin{array}{l}\text { - Tulang patah } \\
\text { - Kerusakan } \\
\text { properti }\end{array}$ & 25 & 10 & 0,5 & 125 & $\begin{array}{l}\text { - Safety helmet } \\
\text { - Safety shoes } \\
\text { - Baju safety } \\
\text { - Safety sign } \\
\text { Briefing } \\
\end{array}$ & 15 & 10 & 0,1 & 15 \\
\hline & & Terpapar kebisingan & $\begin{array}{l}\text { - Ketidaknyamanan } \\
\text { - Gangguan } \\
\text { pendengaran }\end{array}$ & 5 & 10 & 3 & 150 & Tidak ada & 5 & 10 & 3 & 150 \\
\hline \multicolumn{2}{|c|}{$<20$ Acceptable } & \multicolumn{2}{|l|}{ 20-70 Priority 3} & \multicolumn{4}{|c|}{ 180-350 Priority 1} & >350 Very High & & & & \\
\hline
\end{tabular}

Jurnal Dunia Kesmas Vol. 10 No. 1, Januari 2021, hal. 85-95

ISSN 2301-6604 (Print), ISSN 2549-3485 (Online)

http://ejurnalmalayahati.ac.id/index.php/duniakesmas/index 
Tabel 2

Penilaian bahaya dan risiko proses cooking scrap

\begin{tabular}{|c|c|c|c|c|c|c|c|c|c|c|c|c|}
\hline \multirow[t]{2}{*}{ No. } & \multirow[t]{2}{*}{ Proses } & \multirow[t]{2}{*}{ Risiko } & \multirow[t]{2}{*}{ Dampak } & \multicolumn{3}{|c|}{$\begin{array}{c}\text { Analisis Basic } \\
\text { Risik }\end{array}$} & \multirow[t]{2}{*}{$\begin{array}{l}\text { Nilai } \\
\text { Risiko }\end{array}$} & \multirow[t]{2}{*}{ Pengendalian Yang Ada } & \multicolumn{3}{|c|}{$\begin{array}{c}\text { Analisis } \\
\text { Existing Risk }\end{array}$} & \multirow[t]{2}{*}{$\begin{array}{l}\text { Nilai } \\
\text { Risiko }\end{array}$} \\
\hline & & & & $\mathrm{C}$ & $E$ & $\mathrm{~L}$ & & & C & $E$ & $\mathrm{~L}$ & \\
\hline \multirow[t]{7}{*}{1.} & \multirow[t]{7}{*}{$\begin{array}{l}\text { Memasukkan } \\
\text { besi kedalam } \\
\text { tungku }\end{array}$} & Tertusuk material & $\begin{array}{l}\text { - Terluka } \\
\text { - Tergores } \\
\text { - Cidera ringan }\end{array}$ & 5 & 10 & 6 & 300 & $\begin{array}{l}\text { - Safety shoes } \\
\text { - Baju safety } \\
\text { - Sarung tangan }\end{array}$ & 1 & 10 & 3 & 30 \\
\hline & & Terkena ledakan & $\begin{array}{l}\text { - Fatality } \\
\text { - Kerugian materil } \\
\text { - Pencemaran } \\
\text { lingkungan }\end{array}$ & 15 & 10 & 3 & 450 & $\begin{array}{l}\text { - Safety helmet } \\
\text { - Safety shoes } \\
\text { - Baju safety } \\
\text { - Sarung tangan } \\
\text { - SOP } \\
\text { - Safety zone }\end{array}$ & 5 & 10 & 3 & 50 \\
\hline & & Terkena Percikan & $\begin{array}{l}\text { - Luka bakar } \\
\text { - Cidera ringan }\end{array}$ & 5 & 10 & 3 & 150 & $\begin{array}{l}\text { - Safety helmet } \\
\text { - Safety shoes } \\
\text { - Baju safety } \\
\text { - Sarung tangan }\end{array}$ & 5 & 10 & 3 & 150 \\
\hline & & $\begin{array}{l}\text { Terhirup asap dan } \\
\text { debu }\end{array}$ & $\begin{array}{c}\text { - Sesak nafas } \\
\text { Gangguan } \\
\text { pernafasan }\end{array}$ & 5 & 10 & 3 & 150 & Cerobong & 5 & 10 & 3 & 150 \\
\hline & & Terpapar kebisingan & $\begin{array}{l}\text { - Ketidaknyamanan } \\
\text { - Gangguan } \\
\text { pendengaran }\end{array}$ & 5 & 10 & 3 & 150 & Tidak ada & 5 & 10 & 3 & 150 \\
\hline & & Suhu ekstrem & $\begin{array}{l}\text { - Kelelahan } \\
\text { - Iritasi kulit } \\
\text { - Heat cramp } \\
\text { - Dehidrasi }\end{array}$ & 15 & 10 & 3 & 450 & $\begin{array}{l}\text { - Blower } \\
\text { - Kipas angin } \\
\text { - Safety zone } \\
\text { - Penyediaan mineral } \\
\text { botol } \\
\text { - Pergantian kerja }\end{array}$ & 1 & 10 & 1 & 20 \\
\hline & & Posisi janggal & $\begin{array}{l}\text { - Nyeri otot tangan } \\
\text { - Nyeri punggung }\end{array}$ & 5 & 10 & 3 & 150 & $\begin{array}{l}\text { - Training } \\
\text { - Pergantian kerja }\end{array}$ & 1 & 10 & 3 & 30 \\
\hline
\end{tabular}




\begin{tabular}{|c|c|c|c|c|c|c|c|c|c|c|c|c|}
\hline 2. & $\begin{array}{l}\text { Pengoperasian } \\
\text { tungku } \\
\text { menggunakan }\end{array}$ & Tersetrum & Kematian & 50 & 10 & 0,5 & 250 & $\begin{array}{l}\text { - Penyediaan karpet } \\
\text { disekitar tungku } \\
\text { - Safety shoes }\end{array}$ & 25 & 10 & 0,1 & 25 \\
\hline
\end{tabular}

ISSN 2301-6604 (Print), ISSN 2549-3485 (Online)

http://ejurnalmalayahati.ac.id/index.php/duniakesmas/index 


\begin{tabular}{|c|c|c|c|c|c|c|c|c|c|c|c|}
\hline & $\begin{array}{l}\text { tenaga } \\
\text { listrik(PLN) }\end{array}$ & Kebakaran & $\begin{array}{l}\text { - Fatalilty } \\
\text { - Kerugian materil } \\
\text { - Pencemaran } \\
\text { lingkungan } \\
\text { - Dampak sosial } \\
\text { - Tercoreng citra } \\
\text { perusahaan }\end{array}$ & 50 & 10 & \begin{tabular}{l|l}
0,5 & 250
\end{tabular} & \begin{tabular}{|l} 
- SOP \\
- Pemasangan \\
grounding \\
- Hydrant
\end{tabular} & 25 & 10 & 0,1 & 25 \\
\hline$<20$ & Acceptable & 20-70 Priority 3 & 70-180 Substantial & 180 & 50 & ority 1 & >350 Very High & & & & \\
\hline
\end{tabular}

Tabel 3

Penilaian bahaya dan risiko proses analisis laboraturium

\begin{tabular}{|c|c|c|c|c|c|c|c|c|c|c|c|c|}
\hline \multirow[t]{2}{*}{ No. } & \multirow[t]{2}{*}{ Proses } & \multirow[t]{2}{*}{ Risiko } & \multirow[t]{2}{*}{ Dampak } & \multicolumn{3}{|c|}{$\begin{array}{c}\text { Analisis Basic } \\
\text { Risik }\end{array}$} & \multirow[t]{2}{*}{$\begin{array}{c}\text { Nilai } \\
\text { Risiko }\end{array}$} & \multirow[t]{2}{*}{ Pengendalian Yang Ada } & \multicolumn{3}{|c|}{$\begin{array}{c}\text { Analisis } \\
\text { Existing Risk }\end{array}$} & \multirow[t]{2}{*}{$\begin{array}{l}\text { Nilai } \\
\text { Risiko }\end{array}$} \\
\hline & & & & $\mathrm{C}$ & $\mathrm{E}$ & $\mathrm{L}$ & & & $\mathrm{C}$ & $\mathrm{E}$ & $\mathrm{L}$ & \\
\hline 1. & $\begin{array}{l}\text { Cek } \\
\text { kandungan } \\
\text { kimia }\end{array}$ & Bising & $\begin{array}{l}\text { Terpapar } \\
\text { kebisisngan }\end{array}$ & 5 & 10 & 1 & 50 & Tidak ada & 5 & 10 & 1 & 50 \\
\hline \multicolumn{2}{|c|}{$<20$ Acceptable } & 20-70 Priority 3 & 70-180 Substantial & \multicolumn{4}{|c|}{ 180-350 Priority 1} & 350 Very High & & & & \\
\hline
\end{tabular}

Tabel 4

Penilaian bahaya dan risiko proses pencetakan (CCM System)

\begin{tabular}{|c|c|c|c|c|c|c|c|c|c|c|c|c|}
\hline \multirow[t]{2}{*}{ No. } & \multirow[t]{2}{*}{ Proses } & \multirow[t]{2}{*}{ Risiko } & \multirow[t]{2}{*}{ Dampak } & \multicolumn{3}{|c|}{$\begin{array}{c}\text { Analisis Basic } \\
\text { Risik }\end{array}$} & \multirow[t]{2}{*}{$\begin{array}{c}\text { Nilai } \\
\text { Risiko }\end{array}$} & \multirow[t]{2}{*}{ Pengendalian Yang Ada } & \multicolumn{3}{|c|}{$\begin{array}{c}\text { Analisis } \\
\text { Existing Risk }\end{array}$} & \multirow[t]{2}{*}{$\begin{array}{l}\text { Nilai } \\
\text { Risiko }\end{array}$} \\
\hline & & & & $\mathrm{C}$ & $E$ & $\mathrm{~L}$ & & & $\mathrm{C}$ & $\mathrm{E}$ & $\mathrm{L}$ & \\
\hline 1. & $\begin{array}{l}\text { Menuangkan } \\
\text { cairan besi ke }\end{array}$ & $\begin{array}{l}\text { Terkena percikan } \\
\text { besi }\end{array}$ & $\begin{array}{l}\text { - Luka bakar } \\
\text { - Cidera ringan }\end{array}$ & 5 & 10 & 3 & 150 & $\begin{array}{l}\text { - Safety shoes } \\
\text { - Baju safety } \\
\text { - Sarung tangan }\end{array}$ & 5 & 10 & 3 & 150 \\
\hline
\end{tabular}




\begin{tabular}{|l|l|l|l|l|l|l|l|l|l|l|}
$\begin{array}{l}\text { melting } \\
\text { wadah } \\
\text { peleburan } \\
\text { logam }\end{array}$ & $\begin{array}{l}\text { Terpapar } \\
\text { kebisingan }\end{array}$ & $\begin{array}{l}\text { - Ketidaknyamanan } \\
-\begin{array}{l}\text { Gangguan } \\
\text { pendengaran }\end{array}\end{array}$ & 5 & 10 & 3 & 150 & Tidak ada & 5 & 10 & 3 \\
\hline
\end{tabular}

ISSN 2301-6604 (Print), ISSN 2549-3485 (Online)

http://ejurnalmalayahati.ac.id/index.php/duniakesmas/index 


\begin{tabular}{|c|c|c|c|c|c|c|c|c|c|c|c|c|}
\hline 2. & $\begin{array}{l}\text { Wadah } \\
\text { diangkut ke } \\
\text { mesin CCM } \\
\text { dengan } \\
\text { mengunakan } \\
\text { crane } \\
\end{array}$ & Tersiram cairan besi & $\begin{array}{l}\text { - Luka bakar } \\
\text { - Cidera berat }\end{array}$ & 15 & 10 & 0,5 & 75 & $\begin{array}{l}\text { - Jalur khusus } \\
\text { - Safety sign } \\
\text { - SOP }\end{array}$ & 15 & 10 & 0,1 & 15 \\
\hline \multirow[t]{5}{*}{3.} & \multirow[t]{5}{*}{ Pencetakan } & $\begin{array}{l}\text { Terkena percikan } \\
\text { cairan besi }\end{array}$ & $\begin{array}{l}\text { - Luka bakar } \\
\text { - Cidera ringan }\end{array}$ & 5 & 10 & 3 & 150 & $\begin{array}{l}\text { - Safety shoes } \\
\text { - Baju safety } \\
\text { - Sarung tangan }\end{array}$ & 5 & 10 & 3 & 150 \\
\hline & & Terpapar kebisingan & $\begin{array}{l}\text { - Keidaknyamanan } \\
\text { - Gangguan } \\
\text { pendengaran }\end{array}$ & 5 & 10 & 3 & 150 & Tidak ada & 5 & 10 & 3 & 150 \\
\hline & & Suhu panas & $\begin{array}{l}\text { - Kelelahan } \\
\text { - Iritasi kulit } \\
\text { - Heat cramp } \\
\text { - Dehidrasi }\end{array}$ & 5 & 10 & 3 & 150 & $\begin{array}{l}\text { - Kipas angin } \\
\text { - Blower } \\
\text { - Penyedian mineral } \\
\text { botol } \\
\text { - Pergantian kerja }\end{array}$ & 1 & 10 & 1 & 10 \\
\hline & & Terhirup debu & $\begin{array}{l}\text { - Sesak nafas } \\
\text { - Gangguan } \\
\text { pernafasan }\end{array}$ & 5 & 10 & 3 & 150 & Tidak ada & 5 & 10 & 3 & 150 \\
\hline & & Posisi janggal & $\begin{array}{l}\text { - Kaku otot } \\
\text { - Kelelahan }\end{array}$ & 5 & 10 & 3 & 150 & $\begin{array}{l}\text { - Training } \\
\text { - Pergantian kerja }\end{array}$ & 1 & 10 & 3 & 30 \\
\hline \multicolumn{2}{|c|}{$<20$ Acceptable } & 0-70 Priority 3 & 0-180 Substantial & \multicolumn{4}{|c|}{ 180-350 Priority 1} & 350 Very High & & & & \\
\hline
\end{tabular}

Berdasarkan tabel penilaian bahaya dan risiko diatas ditemukan sebanyak 36 macam risiko pada proses kerja steel billet. Hasil perhitungan dari risiko dasar yang ada (basic risk) yang berada pada kategori priority 3 sebanyak 3 risiko ( $8 \%$ ), sebanyak 25 risiko (69\%) berada pada kategori substantial, 6 risiko (17\%) pada kategori priority 1, dan sebanyak 2 risiko (6\%) pada kategori very high. Hasil penilaian basic risk dapat dilihat bahwa risiko yang dapat diterima (acceptable) sebanyak 0 risiko, berarti 36 risiko yang ada pada proses produksi steel billet membutuhkan tindakan pengendalian untuk mengurangi level risiko. Dengan tindakan pengendalian yang telah dilakukan, maka dapat dihitung existing risk. Hasil penilaian existing risk, risiko yang berada pada kategori dapat diterima (acceptable) sebanyak 10 risiko (28\%), sebanyak 11 risiko (30\%) berada pada kategori priority 3 dan 15 risiko ( $42 \%$ ) pada kategori substantial. 


\section{SIMPULAN}

Bahaya dan risiko yang ditemukan di 5 tahapan kerja proses produksi steel billet di PT X Steel Indonesia yang di analisis antara lain adalah tertimpa material, tertabrak material, terpapar kebisingan, tangan terjepit, posisi janggal, mata terkena cahaya, mata terkena percikan, kulit terkena percikan, menghirupasap, tergores material, tertusuk material, terkena ledakan suhu panas, kebakaran dan tersiram cairan besi. Risiko tertinggiyang ditemukan antara lain, pada proses srap adalah terpapar kebisingan dan risiko mata terkena cahaya dengan nilai risiko

150 (substantial), proses cooking scrap adalah terkena percikan, risiko terhirup asap dan debu dan terpapar kebisingan dengan nilai risiko 150 (substantial), proses analisis laboraturium adalah terpapar kebisingan dengan nilai risiko 150 (substantial), Proses pencetakan (CCM system) adalah terkena percikan besi dan risiko terpapar kebisingan dengan nilai risiko 150 (substantial).

\section{SARAN}

Perusahaan perlu melakukan perubahan mulai dari pengukuran pajanan bising, pelatihan ergonomi, Menambah alat pelindung diri (APD) yang adekuat, menyediakan alat pemadam api ringan (APAR), dan meningkatkan pengawasan kepada pekerja khususnya di area cooking scrap.

\section{DAFTAR PUSTAKA}

AS/NZS 4360:1999. (1999). AS/NZS

4360:1999 risk management. AS/NZS

4360:1999, 52.

https://doi.org/AS/NZS 4360

AS/NZS 4360:2004. (2006). AS/NZS 4360

risk management set.

http://www.chchplan.ihp.govt.nz/wpcontent/uploads/2015/03/Exhibit-11-

Risk-Management-Guidelines-Version4360-2004-05032015.pdf

BPJS Ketenagakerjaan. (2016). BPJS Ketenagakerjaan.

Fine WT. (1971). Mathematical evaluation for controlling hazards. Journal of Safety Research, 3(4), 157-166. https://apps.dtic.mil/dtic/tr/fulltext/u2 https://www.ilo.org/wcmsp5/groups/p ublic/---asia/---ro-bangkok/---ilojakarta/documents/publication/wcms_ 627174.pdf

Kementerian Kesehatan RI. (2015). Pusat data dan informasi Kementerian Kesehatan RI.

U.S. Departmen Of Labor. (2018). Job hazard analysis. Accident Prevention and Osha Compliance, 2002, 25-29. https://doi.org/10.1201/97813151365 78-6/722011.pdf

Internasional Labour Organization. (2018). Meningkatkan keselamatan dan kesehatan pekerja muda. 